\title{
RELATION CONTRACTIVE SELFMAPS INVOLVING CAUCHY SEQUENCES
}

\author{
Maria Luigia Diviccaro and Salvatore Sessa \\ Università degli Studi di Napoli Federico II, Dipartimento di Architettura, \\ Via Toledo 402, 80134 Napoli, Italy \\ email: marialuigia.diviccaro@gmail.com,sessa@unina.it
}

\begin{abstract}
We obtain two generalizations of a known theorem of A. Alam and M. Imdad (Fixed Point Theory Appl. 17 (2015) 693-702) showing that some standard proofs can be obtained involving only Cauchy sequences of the successive approximations instead of the usual successive approximations sequences. Suitable examples prove the effective generalization of our results in metric spaces not necessarily complete.
\end{abstract}

Keywords: Cauchy sequence, d-self-closed relation, relation contraction, relation preserving

\section{Introduction}

Fixed point theorems involving contraction conditions under preserving relations are known in literature $(c f$. $[1,2,3,4,5])$. These theorems involve usual sequences of successive approximations in complete metric spaces. Our aim is to prove that extended theorems can be obtained by considering only Cauchy sequences in metric spaces non necessarily complete.

\section{Preliminaries}

We start with some known definitions [1].

Definition 1. Let $\mathrm{X}$ be a non-empty set and_ be a binary relation (eventually partial) defined on $\mathrm{X}$. A sequence $\left\{x_{n}\right\}$ of $X$ is called -preserving if $\left(x_{n}, x_{n+1}\right) \in$ for every $n=0,1,2, \ldots, n, \ldots$.

From now on we consider such binary relations and we write simply $\subseteq \mathrm{X}^{2}$.

Definition 2 ( $c f .[1,4])$. Let $(\mathrm{X}, \mathrm{d})$ be a metric space and $\subseteq \mathrm{X}^{2} . \quad$ is called d-self-closed if whenever $\left\{\mathrm{x}_{\mathrm{n}}\right\}$ is -preserving and converging to a point $x \in X$, then there exists a subsequence $\left\{\mathrm{x}_{\mathrm{n}(\mathrm{k})}\right\}$ of $\left\{\mathrm{x}_{\mathrm{n}}\right\}$ such that either $\left(\mathrm{x}_{\mathrm{n}(\mathrm{k})}, \mathrm{x}\right) \in$ or $\left(\mathrm{x}, \mathrm{x}_{\mathrm{n}(\mathrm{k})}\right) \in$ for every $\mathrm{k}=0,1,2, \ldots$.

Definition 3 ( $c f$. [6]). Let $\mathrm{X}$ be a nonempty set and $\subseteq \mathrm{X}^{2}$. For $\mathrm{x}, \mathrm{y} \in \mathrm{X}$, a -path of length $\mathrm{k}$ (where $\mathrm{k}=0,1,2, \ldots)$ in $\mathrm{X}$ from $\mathrm{x}$ to $\mathrm{y}$ is a finite sequence $\left\{\mathrm{z}_{0}, \mathrm{z}_{1}, \mathrm{z}_{2}, \ldots, \mathrm{z}_{\mathrm{k}}\right\}, 1 \leq \mathrm{k}$, of points of $\mathrm{X}$ satisfying the following conditions:

(i) $\mathrm{z}_{0}=\mathrm{x}$ and $\mathrm{z}_{\mathrm{k}}=\mathrm{y}$,

(ii) $\left(\mathrm{z}_{\mathrm{i}}, \mathrm{Z}_{\mathrm{i}+1}\right) \in$ for each $\mathrm{i}=0, \ldots, \mathrm{k}-1$.

Notice that a path of length $\mathrm{k}$ involves $\mathrm{k}+1$ elements of $\mathrm{X}$, although they are not necessarily distinct. In [2], generalizing a famous theorem of [3], the following theorem was established:

Theorem 1. Let $(X, \leq)$ be a partially ordered set and there exists a metric $d: X \times X \rightarrow[0,+\infty)$. Let $T$ be a selfmap of $\mathrm{X}$ such that

1) $\mathrm{T}$ is monotone non-decreasing, 
2) there exists a point $x_{0} \in X$ such that $x_{0} \leq T\left(x_{0}\right)$,

3) if $\left\{x_{n}\right\}$ is a non-decreasing Cauchy sequence in $X$, then $\left\{x_{n}\right\}$ is converging to a point $z \in X$ and $\mathrm{T}\left(\mathrm{x}_{\mathrm{n}}\right) \leq_{\mathrm{z}}$ for every $\mathrm{n}$,

4) there exists $c \in[0,1)$ such that $d(T(x), T(y)) \leq c \cdot d(x, y)$ for all $(x, y) \in X^{2}$ with $x \geq y$,

then T has a fixed point $w \in X$ such that $x_{0} \leq w$.

In [1], generalizing many theorems contained in the references therein cited, the following theorem was established (not including the case $\mathrm{T}$ continuous considered later):

Theorem 2. Let $(X, d)$ be a complete metric space, $\subseteq X^{2}$ and $T$ be a selfmap of $X$ such that

1) there exists in $X$ a point $x_{0}$ such that $\left(x_{0}, T x_{0}\right) \in$,

2) is $T$-closed, that is $(x, y) \in$ implies $(T x, T y) \in$,

3) is d-self-closed,

4) there exists $\mathrm{c} \in[0,1)$ such that $\mathrm{d}(\mathrm{T}(\mathrm{x}), \mathrm{T}(\mathrm{y})) \leq \mathrm{c} \cdot \mathrm{d}(\mathrm{x}, \mathrm{y})$ for all pair $(\mathrm{x}, \mathrm{y}) \in$.

Then $\mathrm{T}$ has a fixed point. Moreover, if there exists a -path from $\mathrm{x}$ to $\mathrm{y}$ for all $\mathrm{x}, \mathrm{y} \in \mathrm{X}$, then this fixed point is unique.

\section{Unification of Theorems 1 and 2}

Now we unify Theorem 1 and 2 with the following:

Theorem 3. Let $(X, d)$ be a metric space, $\subseteq X^{2}$ and $T$ be a selfmap of $X$. Suppose that

1) there exists in $X$ a point $\mathrm{x}_{0}$ such that $\left(\mathrm{x}_{0}, \mathrm{Tx}_{0}\right) \in$,

2) is T-closed,

3) for any sequence $\left\{y_{n}\right\} \quad$-preserving, $n=0,1,2, \ldots$, which is Cauchy and converging to a point

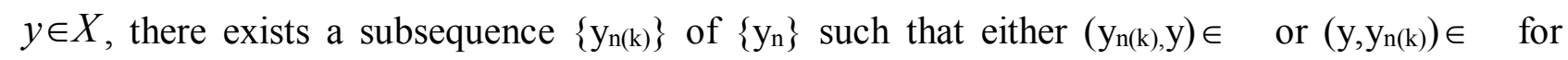
every $\mathrm{k}=0,1,2, \ldots$,

4) there exists $c \in[0,1]$ such that $d(T x, T y) \leq c \cdot d(x, y)$ for all $(x, y) \in$.

Then $\mathrm{T}$ has a fixed point $\mathrm{z}$ in $\mathrm{X}$ and there exists a sequence $\left\{z_{k}\right\}$ such that either $\left(\mathrm{T} z_{k}, z\right) \in$ or $\left(z, \mathrm{Tz}_{k}\right) \in$ for every $\mathrm{k}=0,1,2, \ldots$. Moreover,

5) if there exists a $\quad$-path from $x$ to $y$ for all $x, y \in X$, then this fixed point is unique.

Proof. Let $\mathrm{x}_{0} \neq \mathrm{T} \mathrm{x}_{0}$ otherwise the thesis is trivial. $\mathrm{Put} \mathrm{h}=\mathrm{d}\left(\mathrm{x}_{0}, \mathrm{Tx}_{0}\right)>0$ and $\mathrm{y}_{\mathrm{n}}=\mathrm{T}^{\mathrm{n}}\left(\mathrm{x}_{0}\right)$ for every $\mathrm{n}=0,1,2, \ldots$, so we have $\mathrm{T}^{0} \mathrm{x}_{0}=\mathrm{x}_{0}=\mathrm{y}_{0}, \mathrm{~T}^{1} \mathrm{x}_{0}=\mathrm{Tx}_{0}=\mathrm{Ty}_{0}=\mathrm{y}_{1}, \mathrm{~T}^{2} \mathrm{x}_{0}=\mathrm{Ty}_{1}=\mathrm{y}_{2}, \ldots, \mathrm{Ty}_{\mathrm{n}}=\mathrm{y}_{\mathrm{n}+1}$ for $\mathrm{n}=0,1, \ldots$ Because of properties 1) and 2), the sequence $\left\{\mathrm{y}_{\mathrm{n}}\right\}$ is -preserving. In virtue of property 4$)$, we have that $\mathrm{d}\left(\mathrm{y}_{\mathrm{n}+1}, \mathrm{y}_{\mathrm{n}}\right)=\mathrm{d}\left(\mathrm{T}^{\mathrm{n}+1} \mathrm{x}_{0}, \mathrm{~T}^{\mathrm{n}} \mathrm{x}_{0}\right) \leq \mathrm{c}^{\mathrm{n}} \cdot \mathrm{h}$ for $\mathrm{n}=1,2, \ldots$ and hence $\left\{\mathrm{y}_{\mathrm{n}}\right\}$ is a Cauchy sequence. By property 3$),\left\{y_{n}\right\}$ converges to a point $\mathrm{z}$ in $\mathrm{X}$ and there exists a subsequence $\left\{\mathrm{y}_{\mathrm{n}}(\mathrm{k})\right\}$ of $\left\{\mathrm{y}_{\mathrm{n}}\right\}$ such

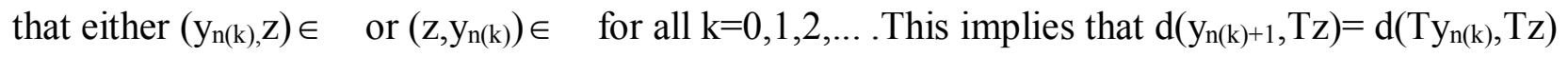




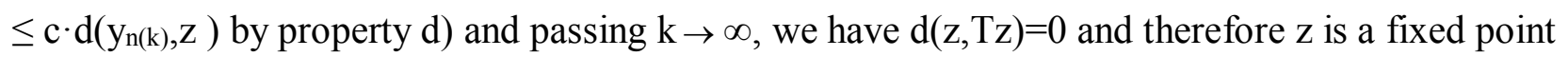
of $\mathrm{T}$. By setting $\mathrm{z}_{\mathrm{k}}=\mathrm{y}_{\mathrm{n}(\mathrm{k})}$ for every $\mathrm{k}=0,1,2, \ldots$, we have $\left(\mathrm{Tz}_{k}, z\right) \in \quad$ if $\left(\mathrm{z}_{\mathrm{k}}, \mathrm{z}\right) \in \quad$ or $\left(z, \mathrm{~T} z_{k}\right) \in$ if $\left(\mathrm{z}, \mathrm{z}_{\mathrm{k}}\right) \in$ for every $\mathrm{k}=0,1,2, \ldots$ because of property $\left.\mathrm{b}\right)$. If property 5$)$ holds, then the fixed point is unique as proved in [2].

Remark 1. Theorem 1 is generalized from Theorem 3 by defining the non-decreasing order " $\leq$ " as relation $\subseteq X^{2}$. Theorem 2 is generalized from Theorem 3 because the condition 3 ) of Theorem 2, i.e. definition 2 , is restricted only to Cauchy sequences and moreover the hypothesis that $\mathrm{X}$ is complete does not appear in Theorem 3 as well.

In the following example Theorem 3, inspired to Example 4 of [2], holds while Theorem 2 is not applicable.

Example 1. Let $\mathrm{X}=\{(\mathrm{x}, \mathrm{x}): \mathrm{x} \in(-1,1]\} \subseteq \mathrm{R}^{2}$ endowed with the Euclidean metric $\mathrm{d}$. Then $(\mathrm{X}, \mathrm{d})$ is a non-complete metric space and define as $((\mathrm{x}, \mathrm{x}),(\mathrm{y}, \mathrm{y})) \in \quad$ iff $\mathrm{x} \leq \mathrm{y}$ and $\mathrm{x} \neq 0, \mathrm{y} \neq 0,((\mathrm{x}, \mathrm{x}),(0,0)) \in$ and $((0,0),(\mathrm{x}, \mathrm{x})) \in \quad$ if $\mathrm{x} \in(-1,1]\}$. Let $\mathrm{c} \in[0,1)$ and define $\mathrm{T}: \mathrm{X} \rightarrow \mathrm{X}$ as $\mathrm{T}((\mathrm{x}, \mathrm{x}))=(\mathrm{cx}, \mathrm{cx})$ if $\mathrm{x}<0$ and $f((x, x))=(0,0)$ if $x \geq 0$. It is immediate to verify that property 1$)$ holds since $((0,0),(0,0))$ $=((0,0),(\mathrm{T} 0, \mathrm{~T} 0)) \in$, moreover properties 2$)$ and 3$)$ hold trivially. Additionally we have that $\mathrm{d}(\mathrm{T}(\mathrm{x}, \mathrm{x}), \mathrm{T}(\mathrm{y}, \mathrm{y}))=\mathrm{d}((\mathrm{kx}, \mathrm{kx}),(\mathrm{ky}, \mathrm{ky}))=2^{1 / 2} \cdot \mathrm{c} \cdot|\mathrm{x}-\mathrm{y}|=\mathrm{c} \cdot \mathrm{d}((\mathrm{x}, \mathrm{x}),(\mathrm{y}, \mathrm{y}))$ if $\mathrm{x}<\mathrm{y}<0, \mathrm{~d}(\mathrm{~T}(\mathrm{x}, \mathrm{x}), \mathrm{T}(\mathrm{y}, \mathrm{y}))$ $=\mathrm{d}((\mathrm{kx}, \mathrm{kx}),(0,0))=2^{1 / 2} \cdot \mathrm{c} \cdot \mathrm{x}=\mathrm{k} \cdot \mathrm{d}((\mathrm{x}, \mathrm{x}),(\mathrm{y}, \mathrm{y}))$ if $\mathrm{x} \leq 0, \mathrm{y}>0, \mathrm{~d}(\mathrm{~T}(\mathrm{x}, \mathrm{x}), \mathrm{T}(\mathrm{y}, \mathrm{y}))=\mathrm{d}((0,0),(0,0))=0<$ $\mathrm{c} \cdot \mathrm{d}((\mathrm{x}, \mathrm{x}),(\mathrm{y}, \mathrm{y}))$ if $0<\mathrm{x} \leq \mathrm{y}$, thus property 4$)$ holds. Also property 5$)$ holds because there exists at least an -path of length 2 , i.e. $((x, x),(0,0)) \in$ and $((0,0),(y, y)) \in$, joining two any points $(x, x)$, $(\mathrm{y}, \mathrm{y})$ of $\mathrm{X}$. Indeed $(0,0)$ is the unique fixed point of $\mathrm{T}$ but Theorem 2 is not applicable because $\mathrm{X}$ is not complete.

Remark 2. If 5) does not hold, Theorem 3 does not guarantee the uniqueness of the fixed point as proved in the following example:

Example 2. Let $X=[0,1]-\{1 / 2\}$ be endowed with metric $d(x, y)=|x-y|$ for all $x, y_{-} \in X$. Define $\subseteq \mathrm{X}^{2}$ as follows: $(\mathrm{x}, \mathrm{y}) \in$ if for all $\mathrm{x}, \mathrm{y}_{-} \in \mathrm{X}$ such that $0 \leq \mathrm{x} \leq \mathrm{y}<1 / 2$ or $1 / 2<\mathrm{x} \leq \mathrm{y} \leq 1$. Then $\mathrm{X}$ is a metric space with the partially defined binary relation . Define $T: X \rightarrow X$ as $T x=x / 2$ if $0 \leq x<1 / 2$ and $\mathrm{Tx}=(\mathrm{x}+1) / 2$ if $1 / 2<\mathrm{x} \leq 1$. Then property 1$)$ holds because $1 / 2<\mathrm{x}_{0} \leq \mathrm{Tx}_{0}$ if $\mathrm{x}_{0} \in(1 / 2,1]$. The property 2 ) holds because $T$ is strictly increasing in both intervals $[0,1 / 2)$ and $(1 / 2,1]$. The property $3)$ holds because it is enough to take strictly increasing sequences in $(1 / 2,1]$. Property 4$)$ holds also for $c=1 / 2$. Property 5) fails because if $\mathrm{x} \in[0,1 / 2]$ and $\mathrm{y} \in(1 / 2,1]$, for any finite -path of length $\mathrm{k}$, $\left\{z_{0}, z_{1}, z_{2}, \ldots, z_{k}\right\}$, there exists at least certainly some $m \in\{0,1, \ldots, k-1)$ such that $z_{m} \in[0,1 / 2)$ and $\mathrm{Z}_{\mathrm{m}+1} \in(1 / 2,1]$, hence $\left(\mathrm{Z}_{\mathrm{m}}, \mathrm{Z}_{\mathrm{m}+1}\right) \notin \quad$. Note that $\mathrm{T}$ has two fixed points which are 0 and 1 .

Remark 3. Theorem 2 is not applicable to Example 2 because $\mathrm{X}$ is not complete.

\section{Relation contractions and continuous selfmaps}

In [2] the following theorem appears:

Theorem 4. Let $(X, \leq)$ be a partially ordered set and there exists a metric $d: X \times X \rightarrow[0,+\infty)$. Let $T$ be a selfmap of $\mathrm{X}$ such that 
1) there exists a point $x_{0} \in X$ such that $x_{0} \leq T\left(x_{0}\right)$,

2) $\mathrm{T}$ is continuous and non-decreasing,

3) if $\left\{\mathrm{x}_{\mathrm{n}}\right\}$ is a non-decreasing Cauchy sequence in $\mathrm{X}$, then $\left\{\mathrm{Tx}_{\mathrm{n}}\right\}$ converges to a point $z \in X$,

4) there exists $c \in[0,1]$ such that $d(T(x), T(y)) \leq c \cdot d(x, y)$ for all $(x, y) \in X^{2}$ with $x \geq y$,

then $\mathrm{T}$ has a fixed point.

In the case $\mathrm{T}$ is assumed continuous, Theorem 2 becomes [1]:

Theorem 5. Let $(X, d)$ be a complete metric space, $\subseteq X^{2}$ and $T$ be a selfmap of $X$ such that

1) There exists at least a point $\left(\mathrm{x}_{0}, \mathrm{Tx}_{0}\right) \in$,

2) is T-closed,

3) $\mathrm{T}$ is continuous,

4) there exists $c \in[0,1]$ such that $d(T(x), T(y)) \leq c \cdot d(x, y)$ for all $(x, y) \in$.

Then $\mathrm{T}$ has a fixed point.

Now we unify Theorems 4 and 5 with the following:

Theorem 6. Let $(X, d)$ be a metric space, $\subseteq X^{2}$ and $T$ be a selfmap of $X$. Suppose that

1) there exists in $X$ a point $x_{0}$ such that $\left(\mathrm{x}_{0}, \mathrm{Tx}_{0}\right) \in$,

2.1) is T-closed,

2.2) T continuous,

3) if $\left\{\mathrm{x}_{\mathrm{n}}\right\}$ is a -preserving Cauchy sequence in $\mathrm{X}$, then $\left\{\mathrm{Tx}_{\mathrm{n}}\right\}$ converging to a point $z \in X$,

4) there exists $c \in[0,1]$ such that $d(T x, T y) \leq c \cdot d(x, y)$ for all $(x, y) \in$.

Then $\mathrm{T}$ has a fixed point in $\mathrm{X}$.

Proof. As in the proof of Theorem 3, let $\mathrm{x}_{0} \neq \mathrm{T} \mathrm{x}_{0}, \mathrm{~h}=\mathrm{d}\left(\mathrm{x}_{0}, \mathrm{~T}_{0}\right)>0$ and $\mathrm{y}_{\mathrm{n}}=\mathrm{T}^{\mathrm{n}}\left(\mathrm{x}_{0}\right)$ for every $\mathrm{n}=0,1,2, \ldots$. Because of properties (1) and (2.1), the sequence $\left\{\mathrm{y}_{\mathrm{n}}\right\}$ is -preserving. In virtue of property 4), we have that $\mathrm{d}\left(\mathrm{y}_{\mathrm{n}+1}, \mathrm{y}_{\mathrm{n}}\right)=\mathrm{d}\left(\mathrm{T}^{\mathrm{n}+1} \mathrm{x}_{0}, \mathrm{~T}^{\mathrm{n}} \mathrm{x}_{0}\right) \leq \mathrm{c}^{\mathrm{n}} \cdot \mathrm{h}$ for $\mathrm{n}=1,2, \ldots$ and hence $\left\{\mathrm{y}_{\mathrm{n}}\right\}$ is a Cauchy sequence. By property 3$),\left\{\mathrm{Ty}_{\mathrm{n}}\right\}$ converges to a point $\mathrm{z}$ and therefore $\left\{\mathrm{TT}_{\mathrm{n}}\right\}=\left\{\mathrm{Ty}_{\mathrm{n}+1}\right\}$ converges to $\mathrm{Tz}$ because of property 2.2), thus $\mathrm{z}=\mathrm{Tz}$ because of the uniqueness of the limit.

Remark 4. Theorem 4 is generalized from Theorem 6 by defining the non-decreasing order " $\leq$ " as relation $\subseteq \mathrm{X}^{2}$. Theorem 5 is generalized from Theorem 6 because if $\left\{\mathrm{x}_{\mathrm{n}}\right\}$ is a -preserving Cauchy sequence in $X$, the completeness of $X$ and the continuity of $T$ assure that $T x_{n}$ converges to a point of $X$, i.e. the property 3 ) of Theorem 6 holds.

The following example shows Theorem 5 is not applicable but Theorem 6 is [2]:

Example 3. Let $X=[0,1]-\{1 / 5\}$ with the metric $d(x, y)=|x-y|$ for all $x, y \in X$. Define $\subseteq X^{2}$ as follows: $(x, y) \in \quad$ if $x \leq y$ for all $x, y_{-} \in X$. Define $T: X \rightarrow X$ as $T x=(x+4) / 5$ for any $x \in X$. Obviously $T$ is continuous in $\mathrm{X}$ and is $\mathrm{T}$-closed. If $\left\{\mathrm{x}_{\mathrm{n}}\right\}$ is a -preserving (that is monotone non-decreasing) 
Cauchy sequence in $\mathrm{X}$, then $\left\{\mathrm{Tx}_{\mathrm{n}}\right\}$ is a monotone non-decreasing bounded sequence and hence converging to a point $z \in X$. Thus properties 1), 2), 3) hold, while 4) holds too because it is enough to assume $\mathrm{k}=1 / 5$. $(\mathrm{X}, \mathrm{d})$ is a metric space not complete, so Theorem 5 is not applicable while all the assumptions of Theorem 6 (or Theorem 4) are satisfied and 1 is the (unique) fixed point of T.

Remark 4. The uniqueness of the fixed point can be guaranteed from several additional properties of the relation $\quad(c f .[1,4,5,7,8,9,10,11])$ which here we do not take under examination.

The following example, borrowed from [1], shows that the continuity of $T$ in Theorem 6 is necessary.

Example 4. Consider $\mathrm{X}=[0,2]$ equipped with usual metric $\mathrm{d}(\mathrm{x}, \mathrm{y})=|\mathrm{x}-\mathrm{y}|$ for all $\mathrm{x}, \mathrm{y} \in \mathrm{X}$. $(X$, d) is a complete metric space. Define $\subseteq X^{2}$ as $=\{(0,0),(0,1),(1,0),(1,1),(0,2)\}$ and $\mathrm{T}: \mathrm{X} \rightarrow$ $\mathrm{X}$ as $\mathrm{T} 0=1 / 4, \mathrm{~T}(\mathrm{x})=0$ if $0<\mathrm{x} \leq 1, \mathrm{~T} x=1$ if $1<\mathrm{x} \leq 2$. is $\mathrm{T}$-closed but $\mathrm{T}$ is not continuous. Consider any -preserving sequence $\left\{\mathrm{x}_{\mathrm{n}}\right\}$, then $\left(\mathrm{x}_{\mathrm{n}}, \mathrm{x}_{\mathrm{n}+1}\right) \in-\{(0,2)\}$ for all $\mathrm{n}=0,1,2, \ldots$. Hence $\mathrm{x}_{\mathrm{n}}=0$ or $\mathrm{x}_{\mathrm{n}}=1$ for all $n=0,1,2, \ldots$. If $\left\{x_{n}\right\}$ is a -preserving Cauchy sequence in $X$, then we have definitively $x_{n}=0$ (resp., $x_{n}=1$ ), i.e. there exists some suitable integer $m$ such that $x_{n}=0$ (resp., $\left.x_{n}=1\right)$ for every integer $\mathrm{n}>\mathrm{m}$, which implies that $\mathrm{Tx}_{\mathrm{n}}=1 / 4$ (resp., $\mathrm{Tx}=0$ ) for all $\mathrm{n}>\mathrm{m}$. Further $\mathrm{d}(\mathrm{T} 0, \mathrm{~T} 0)=\mathrm{d}(\mathrm{T} 1, \mathrm{~T} 1)=0$, $\mathrm{d}(\mathrm{T} 1, \mathrm{~T} 0)=\mathrm{d}(\mathrm{T} 0, \mathrm{~T} 1)=1 / 4 \leq \mathrm{c} \cdot 1=\mathrm{c} \cdot \mathrm{d}(1,0), \mathrm{d}(\mathrm{T} 0, \mathrm{~T} 2)=3 / 4 \leq \mathrm{c} \cdot 2=\mathrm{c} \cdot \mathrm{d}(0,2)$, where $\mathrm{c}=1 / 2$. Thus all the hypothesis of Theorem 6 hold except property 2.2) but $\mathrm{T}$ has no fixed points.

\section{Conclusions.}

We have generalized fixed point theorems for theoretic-relation contractions about continuous selfmaps of metric spaces. Suitable examples prove the effective generalization of our results in metric spaces not necessarily complete.

Future researches shall be necessary for establishing extensions of the results here presented, essentially common fixed point theorems involving Cauchy sequences of Jungck type ( $c f$. [7, 8, 9, $10,11])$, under a more general condition of weak commutativity of two selfmaps.

\section{REFERENCES}

[1] A. Alam, A.R. Khan and M. Imdad, Some coincidence theorems for generalized nonlinear contractions in ordered metric spaces with applications, Fixed Point Theory Appl., 2014 (2014). DOI: $10.1186 / 168718122014216$

[2] A. Alam and M. Imdad, Relation-theoretic contraction principle, J. Fixed Point Theory Appl., 17 (2015), 693-702. DOI 10.1007/s117840150247-y

[3] A. Alam and M. Imdad, Monotone generalized contractions in ordered metric spaces. Bull. Korean Math. Soc., 53 (1) (2016), 61-81. DOI: 10.4134/bkms.2016.53.1.061

[4] A. Alam and M. Imdad, Relation-theoretic metrical coincidence theorems, Filomat 31(14) (2017), 4421-4439. DOI: 10.2298/FIL1714421A

[5] A. Alam, Q.H. Khan and M. Imdad, Comparable nonlinear contractions in ordered metric spaces. J. Nonlinear Sci. Appl., 10 (2017), 1652-1674. DOI:10.22436/jnsa.010.04.29 
[6] M. Berzig, Coincidence and common fixed point results on metric spaces endowed with an arbitrary binary relation and applications, J. Fixed Point Theory Appl., 12 (2012), 221-238.

DOI: $10.1007 / \mathrm{s} 1178401300947$

[7] M.L. Diviccaro, Fixed point theorems for contractions in posets. International Mathematical Forum 4 (35), 1709-1713 (2009). MR2551527, Zb1 1228.54038

[8] B. Kolman, R.C. Busby and S. Ross, Discrete Mathematical Structures, 6 ed., Pearson, London, 2009. ISBN-13: 978-0132297516

[9] J.J. Nieto and R. Rodriguez-Lopez, Contractive mapping theorems in partially ordered sets and applications to ordinary differential equations, Order 22 (3) (2005), 223-239. DOI:

$10.1007 / \mathrm{s} 1108300590185$

[10] M. Turinici, Linear contractions in product ordered metric spaces, Annali dell' Universita' di Ferrara 59 (1) (2013), 187-198. DOI: 10.1007/s1156501201646

[11] W. Sintunavarat, S. Plubtien and P. Katchang, Fixed point result and applications on a b-metric space endowed with an arbitrary binary relation, Fixed Point Theory Appl. 296 (2013). DOI:

10.1186/1687-1812-2013-296 